\title{
Interictal dysphoric disorder: a frequent psychiatric comorbidity among patients with epilepsy who were followed in two tertiary centers
}

Transtorno disfórico interictal: uma comorbidade psiquiátrica frequente entre pacientes com epilepsia acompanhados em dois serviços terciários

Pedro Paulo Gomes do Nascimento 1,2, Carlos Henrique Oliva ${ }^{3}$. Clélia Maria Ribeiro Franco², Lennon Mazetto 1,3, Alberto S. Yamashiro ${ }^{3}$, Gerardo Maria de Araújo Filho ${ }^{1,3}$, Elza Márcia Targas Yacubian ${ }^{1}$

\begin{abstract}
Psychiatric disorders are frequent among patients with epilepsy. Data in the literature have shown a heterogeneous clinical presentation of psychiatric disorders in patients with epilepsy. Interictal dysphoric disorder could be a specific psychiatric comorbidity associated with epilepsy, primarily in patients treated in tertiary centers. Objective: The present study aimed to determine the prevalence of interictal dysphoric disorder among patients with epilepsy who were followed in two tertiary epilepsy services in Brazil. Method: Sixty-five patients with epilepsy completed the Portuguese version of the Interictal Dysphoric Disorder Inventory. Results: Thirty-three (50.7\%) patients fulfilled the diagnostic criteria for interictal dysphoric disorder, although all participants answered positively to having at least one key symptom. Conclusion: The high rate of patients with epilepsy who fulfilled the diagnosis of interictal dysphoric disorder confirms an association between epilepsy and psychiatric disorders. However, there is clearly a need to improve diagnostic tools to allow better differentiation between interictal dysphoric disorder and other psychiatric disorders.
\end{abstract}

Keywords: epilepsy, interictal dysphoric disorder, psychiatric disorders.

RESUMO

Transtornos psiquiátricos são frequentes entre pacientes com epilepsia. Estudos evidenciam apresentações clínicas heterogêneas neste grupo. 0 transtorno disfórico interictal pode um transtorno específico destes pacientes, particularmente naqueles acompanhados em centros terciários. Objetivo: Determinar a prevalência de transtorno disfórico interictal entre pacientes com epilepsia atendidos em dois serviços terciários de epilepsia do Brasil. Método: Sessenta e cinco pacientes foram convidados a responder a versão brasileira do Interictal Dysphoric Disorder Inventory adaptado e validado para o Português. Resultados: Trinta e três pacientes (50,7\%) preencheram critérios para transtorno disfórico interictal, embora todos os entrevistados tenham afirmado que são acometidos por ao menos um dos sintomas-chave. Conclusão: A alta prevalência de transtorno disfórico interictal em pacientes com epilepsia pode ser um indício da associação entre epilepsia e transtornos psiquiátricos. No entanto, é necessário melhorar a acurácia dos instrumentos de diagnóstico para poder diferenciar casos de transtorno disfórico interictal de outros transtornos psiquiátricos.

Palavras-chave: epilepsia, transtorno disfórico interictal, transtornos psiquiátricos.

\section{INTRODUCTION}

Epilepsy is one of the most prevalent neurological conditions and is the most common chronic neurologic disorder in the general population. Studies in the literature indicate that up to $50 \%$ of patients with epilepsy (PWE) have psychiatric disorders (PDs) such as mood, anxiety and psychotic disorders ${ }^{1}$. The appearance of a PD is probably the result of multiple clinical features (e.g., age of onset, type and frequency of seizures, localization of epileptogenic

\footnotetext{
'Department of Neurology and Neurosurgery, Universidade Federal de São Paulo (UNIFESP), São Paulo SP, Brazil;

2 Department of Neurology and Neurosurgery, Universidade Federal de Pernambuco (UFPE), São Paulo SP, Brazil;

${ }^{3}$ Department of Psychiatry, Universidade Federal de São Paulo (UNIFESP), São Paulo SP, Brazil.

Correspondence: Pedro Paulo Gomes do Nascimento; Unidade de Pesquisa e Tratamento das Epilepsias; Rua Napoleão de Barros 737 / 13 andar;

04024-002 São Paulo SP - Brasil; E-mail: ppnasc@yahoo.com.br

Conflict of interest: There is no conflict of interest to declare.
}

Received 08 June 2013; Received in final form 12 June 2013; Accepted 19 June 2013. 
zone, antiepileptic drugs) and psychosocial features (e.g., stigma, familial support $)^{1-3}$.

Psychiatric disorders are not properly recognized and treated among PWE, despite their high prevalence ${ }^{1}$. This could result from two issues. First, the clinical presentation of PDs in PWE may be phenomenologically heterogeneous, suggesting that PDs in epilepsy would be clinically distinct and configure a spectrum in which PD cases comparable to PDs in patients without epilepsy (who fulfill current diagnosis criteria) coexist with subtle PD cases that are not classified according to the criteria of the Diagnostic and Statistical Manual of Mental Disorders, $4^{\text {th }}$ edition (DSM-IV) and the International Classification of Diseases $-10^{\text {th }}$ Revision $(\mathrm{ICD}-10)^{2,4}$. Second, the reluctance to treat these comorbidities may result from traditional beliefs that some symptoms are attributable to antiepileptic medication and that psychiatric drugs should be restricted in patients with epilepsy because the drugs supposedly lower the seizure threshold. Efforts are being made to reverse this situation ${ }^{5}$. The International League Against Epilepsy (ILAE) commission on the psychobiology of epilepsy has evolved through this process and developed an expert consensus that was directed to provide a more comprehensive and acceptable system of classification for PD in epilepsy ${ }^{6}$.

Interictal dysphoric disorder (IDD) was first described by Kraepelin $^{7}$ in 1923. He observed a clinical state in PWE that he called "verstimmungszustand" (i.e., "depressive state"), which comprised intermittent manifestations of psychiatric symptoms that appeared and disappeared faster than in bipolar disorder. In 1984, Himmelhoch ${ }^{8}$ described a "dysthymic interictal subictal state" in patients with a moderate chronic state of depression during seizure-free periods. In describing the same manifestation, Blumer ${ }^{9}$ preferred the term "dysphoric" because this term would be the best translation of Kraepelin's initial idea, especially concerning the frequency and periodicity of the mood swings, irritability, and aggressive outbursts.

More recently, Mula et al. ${ }^{10}$ have developed and operationalized the concept of an IDD diagnosis by forming the Interictal Dysphoric Disorder Inventory (IDDI), which is a 38-item, self-report questionnaire specifically developed to diagnose IDD and to evaluate eight IDD core symptoms in terms of symptom presence, symptom frequency, symptom severity, and global impairment ${ }^{9-11}$. The IDDI was constructed based on the main core symptoms of IDD, characterized by eight key symptoms divided into three categories: (1) labile depressive symptoms (e.g., depressed mood, anergia, pain, insomnia), (2) labile affective symptoms (e.g., panic symptoms and anxiety), and (3) "specific symptoms" (e.g., paroxystic irritability and instable euphoric moods). The Brazilian version of the IDDI (available in the medical literature since 2011) has also allowed a more specific approach to diagnosing IDD in the Brazilian population ${ }^{12}$.
Because there is a scarcity of studies measuring the prevalence and the frequency of core symptoms of IDD among PWE, the present study aimed to determine-through using the IDDIthe prevalence of IDD and to characterize its symptoms in patients treated at two tertiary Brazilian epilepsy services.

\section{METHOD}

From October 2011 to October 2012, all patients were followed up at the outpatient clinic of the Epilepsy Section of the Universidade Federal de São Paulo (São Paulo, Brazil) and Universidade Federal de Pernambuco, Recife (Pernambuco, Brazil). The inclusion criteria were:

1. A diagnosis of epilepsy, based on the ILAE criteria;

2. Age over 18 years;

3. A lack of gross cognitive deficits and a reading ability sufficient to manage the questionnaire;

4. An absence of severe medical diseases;

5. Patient willingness to provide written, informed consent to undergo the experimental procedures.

After providing informed consent, the patients completed a questionnaire eliciting clinical and sociodemographic information such as gender, age, schooling, duration of epilepsy, type and frequency of seizures, and drug treatment. After filling out this initial questionnaire, the patients were assessed through the Portuguese version of the IDDI. As recommended by Mula et al. ${ }^{10}$, patients were considered to have IDD if they had at least three core symptoms that were moderate or severe and caused moderate or severe distress for an period of 12 months.

\section{RESULTS}

Sixty-five $(63.1 \%)$ patients (41 females) with mean age of $35.2 \pm 10.2$ years were included in the study. All patients responded positively to at least one IDD symptom (Figure 1) and $33(50.7 \%)$ patients, $22(66.7 \%)$ of whom were females, fulfilled the diagnostic criteria for IDD. The IDD symptoms are reported for more than $80 \%$ of patients, except insomnia, euphoric moods and panic symptoms, with their occurrence had a similar distribution in both groups (Figure 2).

\section{DISCUSSION}

The present study was aimed at determining the prevalence of IDD and describing its core symptoms in patients treated at two tertiary Brazilian epilepsy services. To our knowledge, this is the first study to use the Brazilian version of IDDI to recognize this possibly very frequent and underdiagnosed psychiatric comorbidity among PWE. 


\section{PREVALENCE OF IDD SYMPTOMS}

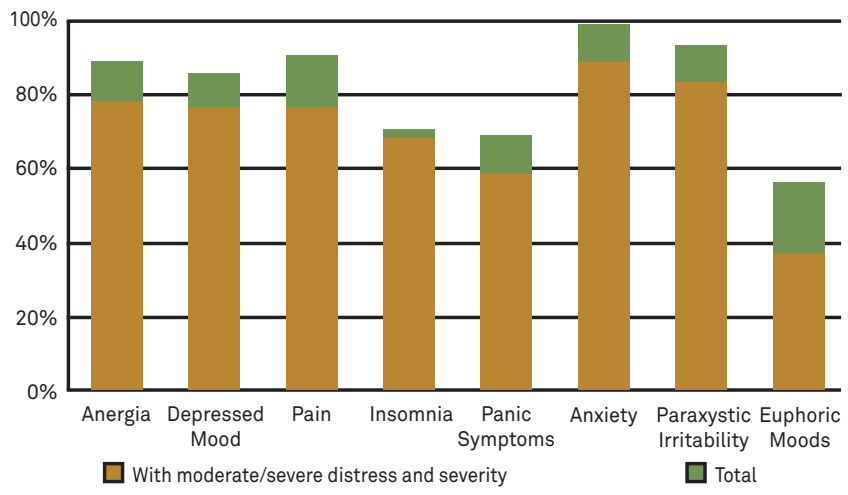

IDD: interictal dystrophic disorder.

Figure 1. The prevalence of interictal dystrophic disorder symptons.

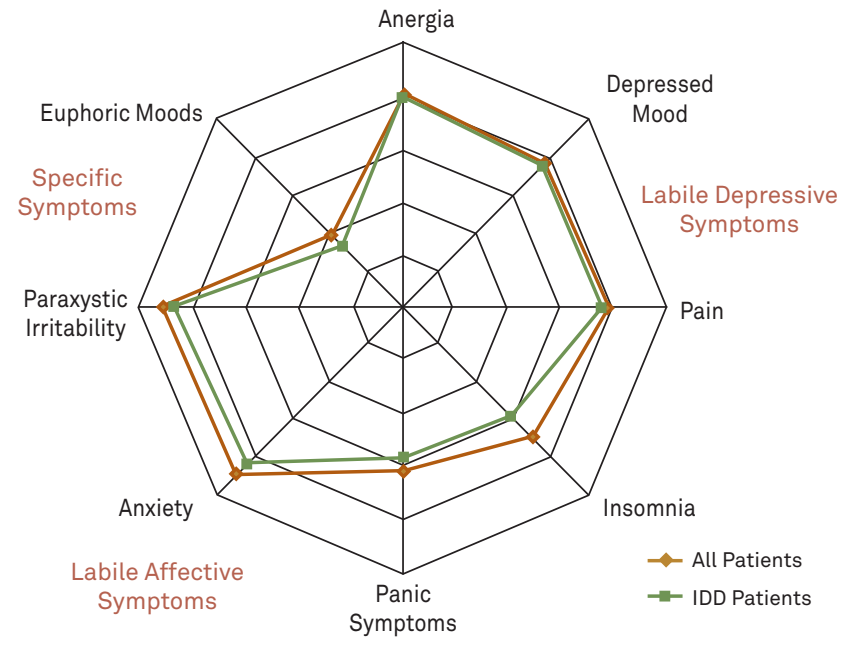

IDD: interictal dystrophic disorder.

Figure 2. Interictal dysphoric disorder symptom frequency with moderate or severe distress and severity.

This study disclosed that IDD was present in $50.7 \%$ of patients, which was similar to the prevalence observed in the study that produced the translation and transcultural adaptation of the Brazilian version of the IDDI ${ }^{12}$. These values were higher than the prevalence of IDD observed in the main medical literature. Himmelhoch ${ }^{8}$ described a $10 \%$ prevalence of patients presenting with "dysthymic symptoms", whereas Mula ${ }^{11}$ found that $21.8 \%$ of patients fulfilled the criteria for IDD. Two reasons that may have contributed to the higher IDD prevalence in the present study are the small number of participants and the presence of other common PDs, such as mood and anxiety disorders. Because the IDDI cannot accurately differentiate IDD symptoms from the symptomatology of other PDs, the concomitant application of other diagnostic psychiatric instruments has been recommended ${ }^{10-12}$.

In the present study, the key symptoms of IDD were highly prevalent. More than $80 \%$ of all patients reported labile depressive and affective symptoms, but specific symptoms such as euphoric mood were observed in only $60 \%$, which has been observed in other studies ${ }^{10,11}$.

The preponderance of depressive and irritability symptoms could be explained, at least partially, by the concept of forced normalization. According to this idea, psychiatric symptoms in PWE could be the consequence of a physiologic or drug-related exacerbation of inhibitory brain activity against the appearance of an exacerbated excitatory epileptic activity ${ }^{9,13}$. Blummer et al. ${ }^{9}$ have suggested that antidepressant drugs are highly effective at lower doses against all IDD symptoms because the drugs antagonize excessive cerebral inhibition. In the same manner, if psychotic symptoms were present, the treatment would be enhanced through the use of antipsychotic medication. However, more studies are necessary to clarify these clinical aspects and to test a pharmacological treatment for IDD and its pathophysiological underpinnings.

In accordance with the medical literature, the present study disclosed a high prevalence of IDD among PWE who were followed in two tertiary epilepsy centers. These results highlight the necessity of improving diagnostic tools such as the Brazilian version of the IDDI to allow better evaluation of IDD and its differentiation from other PDs in PWE. However, the expressive IDD symptoms that result in moderate to severe distress and in moderate to severe severity in PWE demonstrate a real need for improvements in diagnosis and care.

\section{References}

1. Sander JW. The epidemiology of epilepsy revisited. Curr Opin Neurol 2003;16:165-170.

2. Lambert MV, Robertson MM. Depression in epilepsy: etiology, phenomenology, and treatment. Epilepsia 1999;40(Suppl 10):S21-S47.

3. Torta R, Keller, R. Behavioral, psychotic, and anxiety disorders in epilepsy: etiology, clinical features, and therapeutic implications. Epilepsia 1998;40(Suppl)10):S2-S20

4. Titlic M, Basic S, Hajnsek S, et al. Comorbidity psychiatric disorders in epilepsy: a review of literature. Bratislava Med J 2009;110:105-109.

5. Kondziella D, Asztely F. Don't be afraid to treat depression in patients with epilepsy! Acta Neurol Scand 2009;119:75-80
6. Krishnamoorthy ES, Trimble MR, Blumer D. The classification of neuropsychiatric disorders in epilepsy: a proposal by the ILAE Commission on Psychobiology of Epilepsy. Epilepsy Behav 2007;10:349-353.

7. Kraepelin E. Psychiatrie. Band 3. Leipzig, Germany: Johann Ambrosius Barth; 1923.

8. Himmelhoch JM. Major mood disorders related to epileptic changes. In: Blumer D, editor. Psychiatric aspects of epilepsy. Washington, D.C.: American Psychiatric Press, 1984; p. 271-294.

9. Blumer D, Montouris G, Davies K. The interictal dysphoric disorder: recognition, pathogenesis, and treatment of the major psychiatric disorder of epilepsy. Epilepsy Behav 2004;5:826-840. 
10. Mula M, Jauch R, Cavanna A, et al. Clinical and psychopathological definition of the interictal dysphoric disorder of epilepsy. Epilepsia 2008;49:650-656.

11. Mula M, Jauch R, Cavanna A, et al. Interictal dysphoric disorder and periictal dysphoric symptoms in patients with epilepsy. Epilepsia 2010;51:1139-1145.
12. De Araújo Filho $\mathrm{GM}$, de Oliveira $\mathrm{GMN}$, Oliva $\mathrm{CH}$, et al. Tradução e adaptação transcultural do Interictal Dysphoric Disorder Inventory (IDDI) para o Brasil. J Epilepsy Clin Neurophysiol 2010;16:155-161.

13. Krishnamoorthy ES, Trimble MR. Forced normalization: clinical and therapeutic relevance. Epilepsia 1999;40(Suppl 10):S57-S64. 